This is the post-print version of the final paper published in Journal of International Financial Markets, Institutions and Money, 22(1), 1-15, 2012. The published article is available from http://www.sciencedirect.com/science/article/pii/S1042443111000424. Changes resulting from the publishing process, such as peer review, editing, corrections, structural formatting, and other quality control mechanisms may not be reflected in this document. Changes may have been made to this work since it was submitted for publication. Copyright @ 2011 Elsevier B.V.

\title{
The integration of the Credit Default Swap markets during the US subprime crisis: Dynamic correlation analysis ${ }^{1}$
}

Ping Wang, Birmingham Business School, University of Birmingham

Tomoe Moore, Centre for Empirical Finance, Department of Economics and Finance, Brunel University

\begin{abstract}
This paper investigates the integration of the credit default swap (CDS) markets of 38 developed and emerging countries with the US market during the subprime crisis period by utilising dynamic conditional correlation from the multivariate GARCH model. Evidence reveals that the Lehman shock seems to have strengthened the integration, in particular, for developed markets. For both developed and emerging markets, declining US interest rates are found to be the main driving factor behind the higher level of correlation, suggesting that the CDS markets were heavily driven by the world largest economy when the crisis reached its peak.
\end{abstract}

Keywords: Credit Default Swap; Time-varying correlation; GARCH; Credit market integration

JEL Classification: E4, G1

\footnotetext{
${ }^{1}$ We are grateful to an anonymous referee for excellent comments and suggestions. Thanks are also due to the participants of the seminars at the School of Business and Economics, Loughborough University, UK and at the Department of Accounting and Finance, University of Birmingham, UK for their useful comments. All remaining errors are solely of our own responsibility.
} 


\section{Introduction}

The credit default swap (CDS) is a widely traded credit derivative, functioning as an insurance contract for a bondholder, which allows investors to buy protection against a risk of default by corporate or a sovereign entity, referred to as the reference entity. CDS spreads are the annual cost, expressed in basis points against the face value of the bond. It is widely viewed that CDS spreads directly reflect the market's assessment of credit market risk (Longstaff et al 2007), hence the ratings-based assessment of risk has been, in effect, substituted with the use of credit derivatives.

It is argued that CDS spreads are surprisingly highly correlated, and are generally more related to global risk premia and capital flows, implying susceptibility to global financial conditions. The default risk has been transmitted into the CDS, and the market for CDS attracted considerable concern from regulators after a number of large scale incidents in 2008, starting with the collapse of Bear Stearns in March, followed by Lehman Brothers as the largest corporate bankruptcy in September 2008: during the period from the onset of the US subprime crisis in August 2007 until September 2008, the CDS spreads of top US banks increased on average a hundred fold, and the post Lehman shock caused a large upward trend in CDS spreads. The CDS has served to play an endemic role in indicating the depth of the crisis. Hence, with a renewed attention to the CDS market, CDS spreads can be seen as one of the reasonable approximations to gauge the diffusion of the US subprime crisis in global financial markets. For example, Eichengreen et al. (2009) investigate how the common factors influenced the movement of the 45 largest banks' credit swap spreads from the developed economies at different 
phases of the subprime crisis. Using the technique of principal components, they find that the common factors play a major role after the outbreak of the crisis.

Following Lehman's failure in September 2008, the US subprime crisis was transmitted quickly around the world, triggering the global recession. It seems that the developed economies were infected more deeply than emerging economies. This contrasts with the view, which was prevalent before the crisis, that the emerging markets were insulated from adverse shocks from the rest of the world. ${ }^{2}$ This is empirically investigated by Dooley and Hutchison (2009), who analysed the spillover effect of the US subprime crisis on sovereign CDS spreads of emerging markets. Based on the regression analysis of changes to CDS spreads on a series of events and announcements, which are associated with US subprime crisis, they conclude that the emerging markets were somewhat insulated from the subprime crisis before the Lehman shock in 2008, but were infected by the deteriorating situation of the US financial system after the Lehman crisis.

In this paper, we investigate the extent to which CDS markets across countries have become integrated with the US market during the US subprime crisis period from 2007 to 2009. Our analysis is based on the weekly data of 38 sovereign CDS spreads including both developed and emerging markets. Such a relatively large sample set enables us to rigorously scrutinise whether the Lehman shock has strengthened the

\footnotetext{
2 This is either because immature financial markets do not have an adequate mechanism for shocks to be transmitted into the market in the short run, or because emerging markets have undertaken financial reforms, for example, by increasing foreign reserves, reducing government debts and restricting or strictly controlling foreign borrowings (Dooley and Hutchison 2009). The more optimistic view was that emerging economies would continue to grow independently from the subprime crisis, and potentially would help the recovery of developed countries from the US crisis.
} 
linkage with the US market amongst the developed markets and whether it has yielded some turning point in the integration for emerging markets.

Our objective in this study is two-fold. Firstly, we explore the dynamic comovement of the CDS spreads between the US and other countries, for which we utilise the dynamic conditional correlation (DCC) derived from the multivariate GARCH model (Engle 2002) ${ }^{3}$. This represents a significant methodological novelty from the early study of Dooley and Hutchison (2009) in investigating the global spillover of the US subprime crisis. The advantage of this approach is that it can directly demonstrate the evolution of the co-movement of CDS spreads between the US and other developed and emerging markets. A higher correlation between CDS markets implies, generally, a higher comovement and greater integration. The dynamics of correlation, which is time dependent, are modelled together with the volatility of the CDS spreads. By accounting for the timevarying behaviour of data series, possible changes in integration can be detected over time. Hence the timing of shifts in the structural linkages between the US and other markets can be endogenously identified. There is no need for identifying exogenous events that may influence expectations in the US market, as Dooley and Hutchison (2009) elaborated in their work. Secondly, we investigate the driving force behind the dynamic co-movement from the aspect of the potential determinants of default in credit in a linear regression framework. The earlier empirical study finds that the CDS spreads are influenced by common factors, yet little is known about the common factors per se,

\footnotetext{
${ }^{3}$ DCC is often utilised in analysing financial market integration. Kim et al. (2005) adopted the timevariations in conditional correlations from the EGARCH model in the study of developed EU stock markets. See also Chiang et al. (2007) and Wang and Moore (2008), who applied the technique to Asian stock markets and new EU stock markets, respectively.
} 
hence it is of great interest to explore through which channels the linkage of the credit markets is enhanced. To this end, two key variables of domestic stock returns and interest rates, which are frequently cited in literature as determinants of CDS spreads, are specified together with the US stock returns and interest rates as the common factors for the two sets of panel data: one for developed markets and the other for emerging markets. Given the unprecedented largest corporate failure in September 2008, we conduct a closer inspection of the potential shift between the pre- and post-Lehman collapse period ${ }^{4}$.

It is argued that sovereign credit risk may affect the ability to access global debt markets as well as the risk premiums payable to obtain capital. Since sovereign CDSs function as insurance contracts against the event that a sovereign nation defaults on its debt, sovereign CDS spreads directly reflect the market's assessment of a country's credit risk. Hence, understanding the market integration that may be induced by the spillover effect of the US debt market into other markets during the crisis period, would serve to provide useful policy implications for a nation's debt management. Note, also, that the nature of sovereign credit risk determines the characteristics of returns in sovereign debt markets, and therefore affects the diversification of risk in global debt portfolios held by investors. In this respect, this study may offer a valuable insight into the direction for global portfolio management, since the increase (decrease) of market integration would diminish (enhance) the benefits of risk diversification of international financial portfolios.

\footnotetext{
${ }^{4}$ In March, 2008, we also witnessed the near collapse of Bear Sterns, which sent a shockwave around global financial markets. Yet, the scale of the impact was smaller, and its distinctive features were less apparent than with the Lehman crisis. Also, due to relatively small observations between March 2008 and September 2008 with weekly data, we do not pursue the shift arising from Bear Sterns' failure.
} 
These are important issues, in particular, for emerging markets, in which demand for new capital is high, and in which a sizable foreign investment is in place.

Our empirical results reveal that DCC is much higher in developed markets than in emerging markets, yet a higher level of the correlation after the collapse of Lehman Brothers is observed for most countries. Further, it is found that for both developed and emerging markets, the increase in DCC is attributable to the adverse movement of domestic stock returns. However, the most interesting aspect of our findings is that the level of DCC increases more with the common factor of declining US interest rates in the post-Lehman crisis period. This implies that integration between developed and emerging markets is also perceptible during the US subprime crisis.

The rest of the paper is organized as follows. Sections 2 and 3 describe the DCCGARCH model and the data, respectively. The DCC results are shown in Section 4. Section 5 investigates the driving forces of DCC in a linear framework. The conclusion is found in Section 6.

\section{Modelling time-varying conditional correlations}

The bivariate GARCH model with dynamic conditional correlation (DCC) specification (Engle, 2002) is applied to CDS spreads between the US and non-US markets. Let $y_{t}=\left[y_{1 t}, y_{2 t}\right]$ ' be a $2 \times 1$ vector containing the two CDS in a conditional mean equation as follows,

$y_{t}=\mu+\varepsilon_{t} \quad$ and $\quad \varepsilon_{t} \mid \xi_{t-1} \sim N\left(0, H_{t}\right)$

where $\mu$ is a $2 \times 1$ vector of constant, and $\varepsilon_{t}=\left[\varepsilon_{1 t}, \varepsilon_{2 t}\right]$ is a vector of innovations conditional on the information at time $t-1\left(\xi_{t-1}\right)$. The error term is assumed to be 
conditionally multivariate normal with mean zero and variance-covariance matrix, as $H_{t}=D_{t} C_{t} D_{t}$

where $D_{t}$ is a $2 \times 2$ diagonal matrix of the time varying standard deviations from univariate GARCH models with $\sqrt{h_{i, t}}$ on the $i^{\text {th }}$ diagonal. $C_{t}$ is a $2 \times 2$ time-varying symmetric conditional correlation matrix. As indicated, the elements in $D_{t}$ follow the univariate GRACH process of the following:

$h_{i, t}=\omega_{i}+\alpha_{i} \varepsilon_{i, t-1}^{2}+\beta_{i} h_{i, t-1}$

where $\omega_{i}$ is a constant term, $\alpha_{i}$ captures the $\mathrm{ARCH}$ effect, i.e. conditional volatility, and $\beta_{i}$ measures the persistence of the volatility. The evolution of the correlation in the DCC model is given by:

$Q_{t}=\left(1-q_{a}-q_{b}\right) \bar{Q}+q_{a} \varepsilon_{t-1} \varepsilon_{t-1}^{\prime}+q_{b} Q_{t-1}$

where $Q_{t}=\left\{q_{i j}\right\}_{t}$ is a $2 \times 2$ conditional variance-covariance matrix of residuals with its time-invariant variance-covariance matrix $\bar{Q}=E\left(\varepsilon_{t} \varepsilon_{t}^{\prime}\right) . \quad q_{a}$ and $q_{b}$ are nonnegative scalar parameters, satisfying $q_{a}+q_{b}<1$. Because $Q_{t}$ in (4) does not have unit diagonal elements, it is then scaled to get a proper correlation matrix $C_{t}$,

$C_{t}=\operatorname{diag}\left(Q_{t}\right)^{1 / 2} Q_{t} \operatorname{diag}\left(Q_{t}\right)^{-1 / 2}$

A typical element of $C_{t}$ has the form of $\rho_{i j}=q_{i j, t} / \sqrt{q_{i i, t} q_{j j, t}}, i, j=1,2$ and $i \neq j$, which is the key element in this methodology, as it represents the conditional correlation between US and non-US CDS spreads.

\section{Data description}


Weekly data of CDS spreads on five-year sovereign bonds for 38 selected markets were collected from January 2007 to December 2009 with 156 observations $^{5}$. We use sevenyear CDS spreads for the US market, since the five-year CDS data are only available from $11^{\text {th }}$ December 2007, and also the level and movement of the seven-year CDS are almost identical to those of five-year CDS. ${ }^{6}$ All data were retrieved from Datastream.

\section{[Table 1 around here]}

Table 1 provides the descriptive statistics for the 38 sovereign bond CDS spreads, together with the unconditional correlations with the US CDS spreads. The sample is split into two groups of developed and emerging economies based on MSCI market classification $^{7}$, and the latter is further regionally segmented into four areas of New EU,

\footnotetext{
${ }^{5}$ We initially started with 47 CDS markets, of which 9 markets failed to reach the convergence, so we removed them for the further analysis.

${ }^{6}$ The correlation between the five-year and seven-year CDS is 0.998, and the mean values are 30.99 and 32.29 respectively during the period from December 2007 to November 2009, in which the five-year CDS data are available. Hence, rather than starting the sample period from December 2007 based on the fiveyear CDS data availability, which does not cover the onset of crisis, we start January 2007 using the sevenyear CDS data. We argue that judging from the almost perfect correlation between the two maturities of CDS, the difference in the degree of transmission of shocks into either the five-year or seven-year CDS spreads would be very marginal. Also, the main purpose of this paper is to measure the financial integration from the aspect of CDS markets, not to measure the correlation of the specific maturity of CDSs across countries, hence the use of the U.S. seven-year CDS as a proxy to the five-year CDS may be permissible. We note, however, that this caveat needs to be born in mind in interpreting the empirical result.

${ }^{7}$ There are potentially specific features in some emerging markets as compared with developed markets as mentioned in footnote 2, for example, financial markets can be sluggish or government debts and foreign borrowings can be restricted in the post-financial reform period (Dooley and Hutchison 2009). This may be reflected as a different spillover effect of the US market on emerging markets from that on developed markets, and we may not observe a similar market integration with the US between developed and emerging markets,. Hence, we have split the sample countries into the two groups.
} 
Asia, Middle East and Africa, and Latin America ${ }^{8}$. See Appendix for the detail with the country code.

It is noticeable that the mean values of the spreads vary significantly across countries. The developed countries, in general, have relatively low means as compared with emerging markets. The lowest is 18 basis points in Norway (NW) and the highest is 1168 basis points in Pakistan (PK). The other statistics, inducing standard deviation, minimum and maximum, also indicate significant variations. Again, the lowest standard deviation occurs in Norway (NW) at 13.19 basis points, and the highest is found in Pakistan $(\mathrm{PK})$ at 1,024 basis points.

Column 6 in Table 1 is the unconditional correlations of weekly changes in CDS spreads between the US and the other markets. They are all positively correlated with the developed markets having a relatively high correlation, ranging from 0.25 (Japan) to 0.76 (Demark), averaged at 0.58. It is interesting to observe that the CDS spreads in the new EU markets are all correlated with the US market at a similar magnitude between 0.4 to 0.5 , and those in the other markets show declined magnitude, with the lowest one being

\footnotetext{
${ }^{8}$ Note that Israel is classified as a developed market as of May 2010, according to MSCI. This means that this country should be classified as an emerging market during the sample period as in this paper. Further, based on MSCI classification, Lithuania (LN), Romania(Rm), Slovenia(SJ), Bulgraia (BL), Estonia (ET) and Croatia (CT) are classified as Frontier Markets in the region of Europe \& CIS. We put them into the group of new EU for two reasons: firstly they are regionally in or close to the new EU member states; secondly these countries transited from planned to market economy with an opening or re-opening of the capital market, hence we assume that the structure and development of the financial markets in these countries are broadly similar to those of the new member states.
} 
0.17 from Hong Kong. This indicates the degree of integration of the CDS markets within the regional group. ${ }^{9}$

Stationarity in the time series is checked by applying the Augmented Dickey Fuller (ADF) test, see the last two columns in Table 1. The test results suggest that it fails to reject the null of a unit root in the level of CDS series, but overwhelmingly rejects the null for the first difference of the series. Therefore, the differenced series of CDS are used in the DCC-GARCH model.

\section{Estimation and Results}

\section{[Table 2 around here]}

Table 2 is the estimated result from the bivariate DCC-GARCH model. The model is estimated using the quasi-maximum likelihood method to generate consistent standard errors that are robust to non-normality. A closer inspection of the estimated parameters shows that the ARCH parameters, indicated by $\alpha_{2}$, are significant at above 1 percent level for all of the markets. Furthermore, the coefficients for the lagged conditional volatility, as shown by $\beta_{2}$, are significant in most cases, except for Israel (IS), suggesting a high persistence in shocks to the conditional volatility. The effect of time-varying correlation is captured by the coefficients of $q_{a}$ and $q_{b}$, which are the parameters governing the GARCH process of the $\mathrm{Q}$ sequence as in equation (5). The coefficients are overwhelmingly significant at the 5 percent level with 27 out of 38 cases for the

\footnotetext{
${ }^{9}$ The correlation analysis can only be used a guide line analysis for the degree of integration, as Forbes and Rigobon (2002) have argued that the cross market correlations are conditional on market volatility, and if such test is not adjusted for heteroskedasticity, the estimated correlation coefficients can be biased.
} 
coefficient of $q_{a}$, and 34 cases for that of $q_{b}$. Moreover, apart from Indonesia (ID), Pakistan (PK) and Egypt (EG), all of the markets in our sample show a very high significant coefficient of either $q_{a}$ or $q_{b}$ at 1 percent level.

The last two columns in the table report the Ljung-Box Q-statistics for up to the $8^{\text {th }}$ orders in the standardized and squared residuals. It clearly shows the absence of the linear and non-linear serial correlations, except for Greece (GR) and Indonesia (ID), where the serial correlation is significant for the standardized and squared residuals, respectively.

These statistical results indicate that, in general, the data set fit the model specification very well in most of the cases. Therefore, the derived DCC series can provide a reasonable inference on the evolution of correlations over time.

\section{[Figure 1 and Table 3]}

Figure 1 plots the DCC series for each country, where the solid vertical line indicates the event of the Lehman collapse in September 2008. The pattern of correlation considerably varies across developed markets in the pre-Lehman crisis period, then DCC starts showing a similar movement across most of these markets after the Lehman shock. It implies that the Lehman shock contributed to the integration of the CDS markets amongst advanced economies. In the case of the new EU markets, DCC tends to exhibit a similarity of movement over the whole sample period. This applies to other emerging market regions, as well. This is statistically verified by computing the two mean correlations of DCC between developed and emerging markets. We find that the mean correlation of DCC amongst developed markets has increased from 0.18 before the Lehman shock to 0.39 after the shock, whereas that for all the emerging markets remains 
to be similar with 0.57 and 0.54 respectively. It is also noteworthy that the fluctuation of the DCC intensifies for many of these emerging markets in the post-Lehman period, which is not so for the developed markets.

Table 3 presents the descriptive statistics of the DCC series for the pre- and postLehman periods, respectively. By looking at the size of the mean values, the old EU markets in the developed markets have shown themselves to be highly correlated with the US market, manifesting a robust financial integration between the US and developed European markets. It is notable that the DCCs in many developed markets have increased significantly in the post-Lehman period, evidenced by the mean ratio between the pre- and post-periods which exceeds around 1.3 in eleven out of fourteen developed markets, in particular, Germany (BD) and Belgium (BG) experienced a doubling their means with ratios of 2.0 and 2.5 respectively. Amongst emerging markets, Korea (KO) has the highest mean ratio of 1.8. A sharp increase in standard deviation (S.D.) is visible in many emerging markets with the highest S.D. ratio in Hong Kong (HK) at 6.3, followed by Pakistan (PK) at 6.0. The implication of these results is that, in general, the Lehman shock appears to have caused an increase in the CDS market's integration between the US and majority of the developed markets, while such integration is less settled for emerging markets as a whole.

It is argued that the Lehman collapse was largely unanticipated, hence it caused a very direct shock in the real economy and within financial markets worldwide. The contraction of world trade after the Lehman collapse was remarkable, both for its severity and for its uniformity across developed and emerging markets (Dooley and Hutchison 2009). The freezing of credit markets that reached crisis proportions with dysfunctional 
money markets across major developed economies appears to have had a direct effect on international credit markets, including international trade financing (Auboin and MeierEwert 2008). The results are consistent with the historical experience that the correlation in financial variables across countries increases dramatically in periods of crisis.

\section{The determinants of CDS market integration}

Having found the time varying correlation of the CDS spreads, we now examine the driving factors behind the increased correlation in a linear framework for the two sets of panel data: one is for developed markets and the other is for emerging markets. We focus on the two key variables of stock returns and interest rates, which are empirically and theoretically found to be the important determinants of the debt default (e.g. CollinDufresne et al. 2001). The CDS spreads are, effectively, the direct consequence of the default probability, hence the determinants of the default in debts should affect the integration of the CDS markets. The rationale of the two variables included in the analysis is in what follows.

Default is triggered when a firm's value falls below a certain threshold (Longstaff and Schwartz 1995, Zhou 2001, and Collin-Dufresne et al. 2001). The firm's value is unobservable, but since changes in value are induced by changes in the firm's equity value, a fall in stock returns should be accompanied by upward trends in the CDS spread level. This, in turn, affects the dynamic correlation with the US market.

Hull et al (2004) point out that the N-year CDS spread should be theoretically close to the excess of the yield on an $\mathrm{N}$-year bond over the risk-free rate, since a portfolio consisting of a CDS and a bond with certain degree of risk is very similar to a risk-free 
bond. Henceforth, an increase in the risk-free interest rate should have a negative relationship with the CDS spreads. Low interest rates are, indeed, often observed during periods of recession, when the default probability is likely to be high ${ }^{10}$. Hence, the interest rates may exert some impact on DCC.

Note also that the changes in CDS spreads are found to be attributable to the lagged CDS, for example, in Byström (2005) and Alexander and Kaeck (2008), CDS spreads show a severe autocorrelation. Hence, the last-period DCC can be specified as an additional explanatory variable, where persistence of the conditional correlation can be measured. There are number of other variables, which are considered to affect CDS spreads, however, due to a multicollinearity problem and an inadequate data availability for emerging markets, we do not consider other variables in the current study ${ }^{11}$.

Specifically, we estimate the following panel linear model for the DCC:

$$
\begin{aligned}
& d c c_{i, t}=\beta_{i o}+\beta_{i 1} d c c_{i t-1}+\beta_{i 2} e_{i t-1}+\beta_{i 3} \Delta r_{i t-1}+\beta_{i 4} e^{u s}{ }_{i t-1}+\beta_{i 5} \Delta r^{u s}{ }_{i t-1}+\beta_{i 6} d u m * e_{i t-1}+\beta_{i 7} d u m * \Delta r_{i t-1} \\
& +\beta_{i 8} d u m * e^{u s-1}+\beta_{i 9} d u m * \Delta r^{u s}{ }_{i t-1}+u_{i t}
\end{aligned}
$$

\footnotetext{
${ }^{10}$ Duffee (1998) finds a significant, albeit weaker, negative relationship between changes in credit spreads and interest rates. See also Collin-Dufresne et al. (2001), Hull et al (2004), and Alexander and Kaeck (2008).

${ }^{11}$ For example, Collin Dufresne et al (2001), Benkert (2004) and Alexander and Kaeck (2008) use changes in implied volatilities of its publicly traded options. Duffee (1998) argues that the spot rate process itself may depend upon the slope of the term structure (Litterman and Scheinkman, 1991). Some literature on credit risk looks at the linkage between the credit risk and credit ratings. It is also argued that the CDS spreads increase as the domestic currency depreciates relative to the US \$. These factors are empirically found to suffer from multicollinearity in relation to either interest rates or stock returns.
} 
where $e$ is stock returns, $r$ risk-free rates ${ }^{12}$, and $u$ the white noise. The dependent variable $d c c_{i, t}$ is the time varying conditional correlation series derived from the previous section for each country $i$. Given a distinctive feature in the plot and descriptive statistics in DCC between the pre- and post-Lehman collapse period, we have tested the structural shift by the likelihood test. The test statistics overwhelmingly reject the null of no shift between the two periods ${ }^{13}$. We analyse the post-Lehman period by using the dummy variable, taking one for the series of 15 September 2008 onward, and zero otherwise.

There are some studies to investigate the determinants of CDS. For example, Hull et al (2004) examined the relationship between credit swap spreads, bond yields and announcements of credit ratings. Byström (2005) examined the linkage between the spread changes and stock returns to find the leading role of the stock market for the iTraxx indices ${ }^{14}$. Jorion and Zhang (2007) investigated the intra-industry information transfer effect of credit events on credit default swaps and stock markets. Alexander and Kaeck (2008) modeled the five CDS indices using the credit risk model. The innovative nature of the equation (6) is that the determinants of CDS applied to the investigation of CDS market integration, since the dependent variable is the dynamic conditional correlation between US and non-US CDS markets. If we find significant coefficients, this would shed some light on our understanding of market integration and serve to

\footnotetext{
${ }^{12}$ The unit root tests are conducted for the panel data based on Maddala and Wu (1999), Levin et al. (2002) and Im et al. (2003). The interest rates are found to be non-stationary over the sample period, hence, first differenced.

${ }^{13}$ The unrestricted model with the whole sample period and the restricted model with the subsample of the pre-Lehman period are applied to all markets, developed markets and emerging markets, respectively based on equation (6). The likelihood ratio tests are $1859.476,717.965$ and 853.574 for the respective markets with the critical value of 3.84 at a $5 \%$ significance level.

${ }^{14}$ The iTraxx CDS indices consist of the most liquid CDSs in the European and Asian markets.
} 
provide further insight into the debt management and diversification of international portfolios.

The weekly stock returns are constructed as the first difference of logarithmic prices multiplied by 100 based on the stock indices either from MSCI or DS (Datastream). As a proxy for risk-free interest rates, swap rates with a five-year maturity $\operatorname{are~used~}^{15}$. Where the swap rates are not available, other risk free rates such as treasurybill or deposit rates are used. Data are all collected from Datastream.

The estimated coefficients are shown in Table 4. The results are robust in a way that we have obtained a remarkably similar result with either the fixed effect or the random effect in terms of the size and statistical significance of the coefficients.

\section{[Table 4 around here]}

The lagged dependent variables are shown to be statistically highly significant, indicating a strong persistence in the dynamic correlation. It is noteworthy that the size of the significant coefficients between developed and emerging markets is remarkably similar that the persistence is equally strong in both markets. For other significant coefficients, the magnitude is also similar between developed and emerging markets, which indicate that these CDS markets are equally affected by the same determinants.

The Lehman bankruptcy in September 2008 generated a direct financial shock worldwide, as it was largely unanticipated. Given statistically significant coefficients on dummies, it is evident that the shock is also felt on the conditional correlation, which appears to confirm a regime shift in the market integration.

\footnotetext{
${ }^{15}$ Swap rates are highly liquid and are not constrained in short sales and tax regulations (Hull et al. 2004). See also Blanco et al. (2003) for the use of swap rates.
} 
The sensitivity of DCC to domestic stock returns became significant with the Lehman shock. Given a negative sign on $d u m^{*} e_{t-1}$, it may suggest that as domestic stock markets are dampened, the non-US CDS markets become more integrated with the US market. An increase in US interest rates raises the level of DCC before the shock, but declining interest rates accelerate the integration after the shock. The latter is consistent with experience, in that historically low interest rates were observed at the peak of recession in the post-Lehman period, whilst the high probability of default was prevalent in the US economy. Given the relatively large size of the coefficient at around -0.3 on $d u m * \Delta r_{t-1}^{u s}$ as compared with that of $d u m^{*} e_{t-1}$, the effect of the external variable seems to exceed that of the internal variable. This is endorsed by looking at the standardised

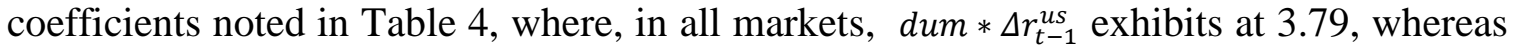
$d u m^{*} e_{t-1}$ shows at $0.22^{16}$. It appears that the sovereign CDS markets were heavily driven by the world's largest economy when the crisis reached its peak. Given the nature of sovereign credit spreads, which are likely to be highly correlated amongst themselves, and are closely related to common global factors, our results are intuitively plausible.

\section{Conclusions}

\footnotetext{
${ }^{16}$ Both variables are, in effect, rates of return; one with stock prices and the other with risk free assets, albeit the latter is first differenced due to non-stationarity. Hence, the magnitude of the coefficients indicates the sensitivity of the DCC against changes in the rates of return of either asset. In this respect, it may not be implausible to compare the magnitude of the coefficients between the two variables. However, in order to support further our argument, we computed the standardised coefficients, though rather in an adhoc manner, by dividing the coefficients by the mean values of the respective variables for the purpose of comparison of the size of the coefficients among these variables.
} 
This paper investigates the integration of sovereign CDS markets with the US market by utilising the dynamic conditional correlation technique. The estimated dynamics of the correlation demonstrate comprehensive evidence of the evolution of the integration during the US subprime-crisis period, as well as the distinctive features of the CDS market integration before and after the Lehman collapse.

We find significant dynamic correlation during the crisis, and the Lehman shock seems to have strengthened the correlation, in particular, for developed markets. The implication is that the effect of risk diversification of international debt portfolios may have been diminished, and also, that the risk premia of sovereign debts would have moved in line with that of the US market in the post-Lehman period.

The linear estimation reveals that, for both developed and emerging markets, DCC is sensitive to the lagged DCC and domestic stock returns. The most worthy of note is that declining US interest rates seem to be the main driving factor behind the higher levels of integration. 


\section{References}

Alexander, C., Kaeck, A., 2008. Regime dependent determinants of credit default swap spreads. Journal of Banking and Finance 32, 1008-1021.

Auboin, M. Meier-Ewert, M. 2008, Improving the availability of trade finance during financial crises. World Trade Organization.

Benkert, C., 2004. Explaining credit default swap premia. Journal of Futures Markets 24, 71-92.

Blanco, R., Brennan, S., Marsh, I.W., 2003. An empirical analysis of the dynamic relationship between investment grade bonds and credit default swaps. Bank of England Working Paper, May.

Byström, H.N.E. 2005. Credit default swaps and equity prices: The iTraxx CDS index market. Lund University, Department of Economics, Working Papers 24.

Chiang, T. C., Jeon, B.N., Li, H., 2007. Dynamic correlation analysis of financial contagion: evidence from Asian markets. Journal of International Money and Finance 26, 1206-1228.

Collin-Dufresne, P., Goldstein, R.S., Martin J.S., 2001. The determinants of credit spread changes. Journal of Finance 6, 2177-2207.

Dooley, M., Hutchison, M. 2009. Transmission of the U.S. subprime crisis to emerging markets: evidence on the decoupling-recoupling hypothesis. Journal of International Money and Finance 28, 1131-1149.

Duffee, G., 1998. The relation between treasury yields and corporate bond yield spreads. Journal of Finance 53, 2225-2241.

Eichengreen, B. Mody, A. Nedeljkovic, M. And Sarno L., 2009. How the subprime crisis went global: evidence from bank credit default swap spreads, NBER working paper No. 14904.

Engle, R., 2002. Dynamic conditional correlation: A simple class of multivariate generalized autoregressive conditional Heteroskedasticity models. Journal of Business and Economic Statistics 20, 339-350.

Forbes, K.J and R. Rigobon (2002). No contagion, only interdependence: measuring stock market comovements. The Journal of Finance 57, 2223-2261.

Hull, J., Predescu, M., White, W., 2004. The relationship between credit default swap spreads, bond yields and credit rating announcements. Journal of Banking and Finance 28, 2789-2811. 
Im, K.S., Pesaran, M.H., Shin, Y. 2003. Testing for unit roots in heterogeneous panels. Journal of Econometrics 115, 53-74.

Jorion, P., Zhang, G. 2007. Good and bad credit contagion: Evidence from credit default swaps. Journal of Financial Economics 84, 860-883.

Kim, S.J., Moshirian, F., Wu, E., 2005. Dynamic stock market integration driven by the European Monetary Union: an empirical analysis. Journal of Banking and Finance $29,2475-2502$.

Levin, A., Lin, C.F., Chu, C.S., 2002. Unit root tests in panel data: Asymptotic and finite-sample properties. Journal of Econometrics 108, 1-24.

Litterman, R.B., Scheinkman, J., 1991. Common factors affecting bond returns. The Journal of Fixed Income 1, 54-61.

Longstaff, F.A, Schwartz, E.S., 1995. A simple approach to valuing risky fixed and floating rate debt. Journal of Finance 60, 2213-2253.

Longstaff, F. A., Pan, J., Pedersen, L.H., Singleton, K.J., 2007. How sovereign is sovereign credit risk? NBER Working paper, no13658.

Maddala, G.S., Wu, S., 1999. A comparative study of unit root tests with panel data and a new simple test. Oxford Bulletin of Economics and Statistics 61, 631-652.

Wang, P., Moore, T., 2008. Financial Market integration for the transition economies: time-varying conditional correlation approach. The Manchester School 76, 116133.

Zhou, C., 2001. The term structure of credit spreads with jump risk. Journal of Banking and Finance 25, 2015-2040. 


\section{Appendix}

Developed and emerging markets with country code (total 38 markets)

Developed markets (14):

Denmark (DN), France (FR), Germany (BD), Greece (GR), Iceland (IC), Ireland (IR), Italy (IT), Japan (JP), Norway (NW), New Zealand (NZ), Spain (ES), Sweden (SD), Austria (OE), Belgium (BG)

Emerging markets (24):

New EU

Czech Republic (CZ), Hungary (HN), Lithuania (LN), Poland (PO), Romania (RM), Slovenia (SJ), Bulgaria (BL), Estonia (ET), Croatia (CT)

Asia

China (CH), Hong Kong (HK), Indonesia (ID), South Korea (KO), Malaysia (MY), Pakistan (PK), Thailand (TH)

Middle East and Africa

Egypt (EG), Israel (IS), South Africa (SA), Turkey (TK)

Latin America

Brazil (BR), Chile (CL), Colombia (CB) and Peru (PE) 
Table 1 Preliminary analysis of CDS spreads in basis points

\begin{tabular}{|c|c|c|c|c|c|c|c|}
\hline Country & Mean & Std.Dev. & Minimum & Maximum & Correlation & $\begin{array}{l}\mathrm{ADF} \\
\text { level }\end{array}$ & $\begin{array}{c}\text { ADF } \\
1^{\text {st }} \text { diff }\end{array}$ \\
\hline \multicolumn{8}{|c|}{ a) Developed markets } \\
\hline US & 26.37 & 20.70 & 0.90 & 99.47 & 1.00 & -1.40 & -11.97 \\
\hline DN & 32.38 & 36.95 & 2.00 & 142.29 & 0.76 & -1.30 & -11.21 \\
\hline FR & 21.07 & 21.69 & 0.50 & 96.08 & 0.71 & -1.34 & -11.59 \\
\hline $\mathrm{BD}$ & 18.22 & 19.62 & 0.90 & 91.03 & 0.70 & -1.42 & -11.43 \\
\hline GR & 84.70 & 81.65 & 4.40 & 289.28 & 0.59 & -0.30 & -4.22 \\
\hline IC & 366.26 & 363.91 & 1.60 & 1304.10 & 0.27 & -1.37 & -10.96 \\
\hline IR & 87.61 & 96.84 & 1.80 & 378.40 & 0.60 & -1.18 & -12.13 \\
\hline IT & 58.62 & 53.31 & 5.30 & 199.07 & 0.64 & -1.05 & -12.14 \\
\hline JP & 30.60 & 25.38 & 2.40 & 110.00 & 0.25 & -1.70 & -13.07 \\
\hline NW & 18.30 & 13.19 & 1.07 & 65.33 & 0.70 & -1.95 & -12.81 \\
\hline NZ & 40.09 & 45.64 & 7.57 & 235.56 & 0.41 & -2.04 & -10.05 \\
\hline ES & 48.49 & 41.50 & 2.50 & 156.80 & 0.65 & -1.02 & -14.41 \\
\hline SD & 43.66 & 37.32 & 1.00 & 158.90 & 0.56 & $-2.69 *$ & -16.55 \\
\hline $\mathrm{OE}$ & 47.12 & 58.87 & 0.50 & 267.18 & 0.68 & -1.45 & -11.06 \\
\hline BG & 33.56 & 34.57 & 1.60 & 152.20 & 0.65 & -1.41 & -12.13 \\
\hline \multicolumn{8}{|l|}{ b) New EU } \\
\hline $\mathrm{CZ}$ & 71.30 & 76.14 & 4.50 & 342.13 & 0.53 & -1.51 & -11.46 \\
\hline $\mathrm{HN}$ & 186.78 & 164.96 & 16.10 & 638.44 & 0.40 & -1.53 & -10.67 \\
\hline $\mathrm{LN}$ & 243.08 & 232.60 & 3.60 & 847.37 & 0.46 & -1.37 & -9.78 \\
\hline $\mathrm{PO}$ & 99.74 & 97.94 & 6.80 & 405.00 & 0.50 & -1.37 & -12.01 \\
\hline $\mathrm{RM}$ & 232.82 & 208.32 & 17.50 & 755.89 & 0.44 & -1.52 & 10.00 \\
\hline SJ & 53.65 & 50.65 & 3.80 & 258.10 & 0.50 & -1.72 & -5.57 \\
\hline $\mathrm{BL}$ & 205.67 & 182.28 & 13.00 & 698.16 & 0.46 & -1.37 & -10.99 \\
\hline $\mathrm{CT}$ & 165.78 & 150.90 & 15.20 & 600.00 & 0.50 & -1.34 & -10.47 \\
\hline ET & 206.50 & 201.43 & 4.80 & 730.74 & 0.44 & -1.46 & -9.61 \\
\hline \multicolumn{8}{|l|}{ c) Asia } \\
\hline $\mathrm{CH}$ & 74.78 & 64.03 & 9.00 & 278.30 & 0.33 & -1.45 & 12.28 \\
\hline HK & 48.80 & 39.42 & 1.40 & 158.40 & 0.17 & -1.61 & -13.93 \\
\hline ID & 288.03 & 201.57 & 92.20 & 1158.30 & 0.22 & -2.22 & -14.45 \\
\hline $\mathrm{KO}$ & 130.51 & 126.43 & 14.20 & 700.00 & 0.26 & -2.34 & -11.65 \\
\hline MY & 102.89 & 85.14 & 12.00 & 448.30 & 0.27 & -1.51 & -13.18 \\
\hline PK & 1168.43 & 1024.40 & 152.80 & 5105.70 & 0.21 & -1.63 & -7.25 \\
\hline $\mathrm{TH}$ & 115.01 & 80.69 & 27.20 & 456.20 & 0.28 & -1.65 & -12.87 \\
\hline \multicolumn{8}{|c|}{ d) Middle East and Africa } \\
\hline EG & 254.46 & 195.38 & 68.50 & 731.90 & 0.23 & -1.25 & -6.61 \\
\hline IS & 91.87 & 67.57 & 15.50 & 285.41 & 0.45 & -1.48 & -12.75 \\
\hline SA & 173.82 & 133.15 & 23.80 & 587.90 & 0.38 & -1.71 & -6.52 \\
\hline TK & 257.68 & 109.69 & 136.30 & 787.70 & 0.29 & $-2.55^{*}$ & 11.76 \\
\hline \multicolumn{8}{|c|}{ e) Latin America } \\
\hline $\mathrm{BR}$ & 163.25 & 99.32 & 62.10 & 536.70 & 0.27 & -1.54 & -17.81 \\
\hline CL & 85.02 & 75.94 & 12.50 & 305.00 & 0.29 & -1.32 & -15.72 \\
\hline $\mathrm{CB}$ & 192.69 & 102.19 & 64.70 & 535.40 & 0.30 & -1.62 & -17.46 \\
\hline PE & 168.76 & 104.43 & 59.90 & 534.20 & 0.28 & -1.56 & -17.09 \\
\hline
\end{tabular}

Note: For the ADF test, the choice of lag length is based on Schwarz Information Criterion. The critical values at $1 \%, 5 \%$ and $10 \%$ significant levels are $-3.47,-2.88$ and -2.58 , respectively. 
Table 2 Estimates of DCC - GARCH model

\begin{tabular}{|c|c|c|c|c|c|c|c|c|}
\hline & $\alpha_{1}$ (t-ratio) & $\alpha_{2}$ (t-ratio) & $\beta_{1}$ (t-ratio) & $\beta_{2}$ (t-ratio) & $\mathrm{q}_{\mathrm{a}}$ (t-ratio) & $\mathrm{q}_{\mathrm{b}}$ (t-ratio) & $\mathrm{Q}$ & $\mathrm{Q}^{2}$ \\
\hline \multicolumn{9}{|c|}{ a) Developed markets } \\
\hline $\mathrm{DN}$ & $0.45(2.94)$ & $0.36(3.25)$ & $0.56(6.28)$ & $0.61(9.33)$ & $0.26(4.77)$ & $0.73(14.1)$ & $10.98[0.20]$ & $12.16[0.14]$ \\
\hline FR & $0.31(2.48)$ & $0.62(2.41)$ & $0.69(7.64)$ & $0.50(6.10)$ & $0.45(7.95)$ & $0.50(7.79)$ & $7.77[0.46]$ & $1.57[0.99]$ \\
\hline $\mathrm{BD}$ & $0.23(2.73)$ & $0.40(2.85)$ & $0.77(13.1)$ & $0.67(10.7)$ & $0.30(5.11)$ & $0.69(10.9)$ & $5.23[0.73]$ & $0.62[1.00]$ \\
\hline GR & $1.53(3.97)$ & $1.40(5.55)$ & $0.22(2.67)$ & $0.55(14.1)$ & $0.61(6.06)$ & $0.27(1.61)$ & $17.95[0.02]$ & $11.79[0.16]$ \\
\hline IC & $0.63(2.75)$ & $1.04(4.94)$ & $0.55(5.23)$ & $0.53(10.3)$ & 0.35 (4.29) & 0.55 (4.78) & $8.55[0.38]$ & $8.58[0.38]$ \\
\hline $\mathrm{IR}$ & $0.38(1.81)$ & $0.29(3.62)$ & $0.62(4.95)$ & $0.74(17.4)$ & $0.19(2.31)$ & $0.74(6.69)$ & $7.00[0.54]$ & $4.63[0.80]$ \\
\hline IT & $1.01(2.78)$ & $1.67(3.91)$ & $0.42(3.19)$ & $0.44(6.91)$ & $0.48(6.61)$ & $0.43(4.47)$ & $14.00[008]$ & $13.30[0.10]$ \\
\hline JP & $0.50(2.23)$ & $1.62(3.81)$ & $0.53(4.47)$ & $0.37(6.49)$ & $0.02(0.65)$ & $0.97(21.5)$ & $5.75[0.66]$ & $4.59[0.80]$ \\
\hline NW & $0.19(2.94)$ & $0.18(2.89)$ & $0.74(11.8)$ & $0.69(6.92)$ & $0.29(2.74)$ & $0.55(2.57)$ & $10.29[0.25]$ & $3.73[0.88]$ \\
\hline $\mathrm{NZ}$ & $0.19(6.74)$ & $0.24(2.65)$ & $0.75(73.3)$ & $0.43(28.4)$ & $0.02(1.41)$ & $0.98(87.3)$ & $8.13[0.42]$ & $0.11[1.00]$ \\
\hline ES & $0.75(3.07)$ & $2.04(4.25)$ & $0.51(5.47)$ & $0.40(5.82)$ & $0.31(6.91)$ & $0.67(14.5)$ & $7.44[0.49]$ & $3.53[090]$ \\
\hline SD & $0.32(1.60)$ & $0.09(4.58)$ & $0.64(5.51)$ & $0.87(70.6)$ & $0.03(18.1)$ & $0.97(84.7)$ & $6.38[060]$ & $7.31[0.50]$ \\
\hline $\mathrm{OE}$ & $0.45(1.96)$ & $0.61(3.68)$ & $0.58(5.74)$ & $0.57(10.0)$ & $0.10(1.10)$ & $0.89(15.1)$ & $3.98[0.86]$ & $7.330 .50]$ \\
\hline BG & $0.80(3.51)$ & $1.97(4.56)$ & $0.52(8.03)$ & $0.41(6.68)$ & $0.28(5.41)$ & $0.71(14.4)$ & $4.91[0.77]$ & $1.53[0.99]$ \\
\hline \multicolumn{9}{|c|}{ b) New EU markets } \\
\hline $\mathrm{CZ}$ & $0.57(7.96)$ & $1.65(11.1)$ & $0.51(17.4)$ & $0.45(25.2)$ & $0.05(50.5)$ & $0.95(130.3)$ & $7.75[0.46]$ & $4.83[0.76]$ \\
\hline $\mathrm{HN}$ & $1.03(2.23)$ & $0.68(4.25)$ & $0.26(2.14)$ & $0.42(5.96)$ & $0.24(3.83)$ & $0.72(11.7)$ & $8.60[0.38]$ & $3.31[0.91]$ \\
\hline $\mathrm{LN}$ & $0.51(2.13)$ & $0.55(3.74)$ & $0.48(3.70)$ & $0.52(6.44)$ & $0.21(2.32)$ & $0.59(4.30)$ & $15.4[0.05]$ & $7.79[0.45]$ \\
\hline PO & $1.33(3.22)$ & $0.65(4.78)$ & $0.19(2.66)$ & $0.50(9.11)$ & $0.14(2.36)$ & $0.81(12.4)$ & $5.60[0.69]$ & $9.29[0.32]$ \\
\hline $\mathrm{RM}$ & $1.58(2.84)$ & $1.07(2.61)$ & $0.21(2.78)$ & $0.50(7.36)$ & $0.24(3.11)$ & $0.71(8.00)$ & $8.53[0.39]$ & $1.75[0.99]$ \\
\hline SJ & $0.56(2.28)$ & $1.53(4.98)$ & $0.49(4.23)$ & $0.27(4.90)$ & $0.20(3.00)$ & $0.79(13.3)$ & $7.60[0.47]$ & $3.70[0.88]$ \\
\hline BL & $1.29(2.33)$ & $0.74(4.71)$ & $0.24(2.13)$ & $0.50(9.47)$ & $0.18(2.14)$ & $0.76(10.2)$ & $7.63[0.47]$ & $6.98[0.54]$ \\
\hline CT & $1.20(1.61)$ & $0.93(3.49)$ & $0.28(1.33)$ & $0.48(9.72)$ & $0.31(2.74)$ & $0.67(7.81)$ & $11.4[0.18]$ & $5.94[0.65]$ \\
\hline ET & $0.70(1.60)$ & $0.46(4.11)$ & $0.41(2.07)$ & $0.63(11.2)$ & $0.15(1.79)$ & $0.78(9.29)$ & $13.05[0.11]$ & $4.35[0.82]$ \\
\hline
\end{tabular}

c) Asian markets 


\begin{tabular}{|c|c|c|c|c|c|c|c|c|}
\hline $\mathrm{CH}$ & $1.42(2.49)$ & $1.84(4.58)$ & $0.23(2.44)$ & $0.33(5.69)$ & $0.29(1.85)$ & $0.61(3.27)$ & $8.88[0.35]$ & $6.63[0.58]$ \\
\hline HK & $0.53(2.41)$ & $0.33(2.04)$ & $0.51(4.56)$ & $0.25(1.58)$ & $0.06(0.79)$ & $0.79(3.23)$ & $3.54[0.90]$ & $0.38[1.00]$ \\
\hline ID & $0.71(9.60)$ & $1.10(8.02)$ & $0.40(18.6)$ & $0.10(11.6)$ & $0.00(0.00)$ & $0.27(0.19)$ & $14.81[0.06]$ & $24.46[0.002]$ \\
\hline KO & $1.46(2.92)$ & $1.17(5.41)$ & $0.20(2.68)$ & $0.45(10.8)$ & $0.26(2.59)$ & $0.69(5.59)$ & $9.53[0.30]$ & $4.13[0.84]$ \\
\hline MY & $1.46(3.18)$ & $0.85(3.73)$ & $0.19(2.88)$ & $0.47(6.94)$ & $0.25(2.74)$ & $0.70(6.79)$ & $7.86[0.45]$ & $2.29[0.97]$ \\
\hline PK & $0.50(2.40)$ & $0.91(3.37)$ & $0.53(4.73)$ & $0.40(6.05)$ & $0.23(1.22)$ & $0.32(1.06)$ & $3.99[0.86]$ & $1.44[0.99]$ \\
\hline $\mathrm{TH}$ & $1.56(3.54)$ & $0.87(4.94)$ & $0.18(3.01)$ & $0.49(6.73)$ & $0.27(3.09)$ & $0.68(6.93)$ & $9.41[0.31]$ & $4.46[0.81]$ \\
\hline \multicolumn{9}{|c|}{ d) Middle East and African markets } \\
\hline EG & $0.65(12.8)$ & $0.39(15.2)$ & $0.49(27.6)$ & $0.60(29.8)$ & $0.03(1.36)$ & $0.00(0.00)$ & $12.37[0.14]$ & $0.56[1.00]$ \\
\hline IS & $0.46(2.34)$ & $1.44(3.20)$ & $0.53(4.61)$ & $0.12(1.40)$ & $0.32(2.54)$ & $0.47(3.07)$ & $6.55[0.59]$ & $5.24[0.73]$ \\
\hline SA & $1.35(2.98)$ & $1.08(3.44)$ & $0.22(3.18)$ & $0.37(5.96)$ & $0.26(3.32)$ & $0.69(8.22)$ & $9.81[0.28]$ & $6.41[0.60]$ \\
\hline TK & $0.77(1.84)$ & $0.65(3.17)$ & $0.40(2.30)$ & $0.34(3.73)$ & $0.24(2.95)$ & $0.72(12.2)$ & $7.40[0.49]$ & 7.72[0.46] \\
\hline \multicolumn{9}{|c|}{ e) Latin American markets } \\
\hline BR & $0.63(2.34)$ & $0.59(3.49)$ & $0.46(3.95)$ & $0.50(8.18)$ & $0.15(1.61)$ & $0.73(7.86)$ & $4.31[0.83]$ & $5.91[0.66]$ \\
\hline $\mathrm{CL}$ & $0.54(2.33)$ & $1.03(4.33)$ & $0.50(4.37)$ & $0.45(7.79)$ & $0.14(1.32)$ & $0.73(6.89)$ & $10.75[0.22]$ & $3.01[0.93]$ \\
\hline CB & $1.32(2.40)$ & $0.83(2.80)$ & $0.23(2.11)$ & $0.42(3.92)$ & $0.24(3.02)$ & $0.70(8.79)$ & $3.90[0.87]$ & $3.69[0.88]$ \\
\hline PE & $1.30(2.45)$ & $1.20(3.95)$ & $0.22(2.15)$ & $0.27(3.74)$ & $0.20(2.61)$ & $0.72(8.48)$ & $5.25[0.73]$ & $5.66[0.69]$ \\
\hline
\end{tabular}

Note: In order to save spaces, only GARCH parameters are reported here. The other estimates are available from the authors upon request.

The numbers in brackets are t-ratios. The critical values are $2.33,1.96$ and 1.65 at the $1 \%, 5 \%$ and $10 \%$ significant levels, respectively.

$\mathrm{Q}$ and $\mathrm{Q}^{2}$ are the Ljung-Box Q-statistics up to the $8^{\text {th }}$ orders in the standardized and the squared residuals, respectively.

The critical values are $13.4,15.5$ and 20.1 at the $1 \%, 5 \%$ and $10 \%$ significance levels, respectively. The numbers in square brackets are the significant values. 
Table 3 Descriptive statistic of dynamic correlation: Pre-Lehman and Post-Lehman periods

\begin{tabular}{|c|c|c|c|c|c|c|c|c|c|c|}
\hline & Mean & $\begin{array}{l}\text { Std. Dev. } \\
\text { Pre-Lehn }\end{array}$ & $\begin{array}{l}\text { Max } \\
\text { an crisis }\end{array}$ & Min & Mean & $\begin{array}{l}\text { Std. Dev. } \\
\text { Post-Lel }\end{array}$ & $\begin{array}{c}\text { Max } \\
\text { an crisis }\end{array}$ & Min & \multirow[t]{2}{*}{$\begin{array}{l}\text { Mean } \\
\text { ratio }\end{array}$} & \multirow[t]{2}{*}{$\begin{array}{l}\text { S.D. } \\
\text { Ratio }\end{array}$} \\
\hline \multicolumn{9}{|c|}{ a) Developed markets } & & \\
\hline $\mathrm{DN}$ & 0.611 & 0.258 & 0.991 & -0.045 & 0.783 & 0.131 & 0.967 & 0.367 & 1.282 & 0.507 \\
\hline FR & 0.568 & 0.206 & 0.910 & -0.093 & 0.800 & 0.160 & 0.992 & 0.230 & 1.407 & 0.778 \\
\hline $\mathrm{BD}$ & 0.406 & 0.269 & 0.921 & -0.269 & 0.820 & 0.158 & 0.970 & 0.200 & 2.021 & 0.587 \\
\hline GR & 0.503 & 0.214 & 0.790 & -0.698 & 0.702 & 0.276 & 0.982 & -0.498 & 1.395 & 1.291 \\
\hline IC & 0.277 & 0.104 & 0.764 & 0.023 & 0.289 & 0.258 & 0.907 & -0.613 & 1.043 & 2.480 \\
\hline IR & 0.517 & 0.107 & 0.741 & 0.202 & 0.684 & 0.115 & 0.846 & 0.355 & 1.325 & 1.078 \\
\hline IT & 0.531 & 0.183 & 0.786 & -0.215 & 0.761 & 0.195 & 0.979 & -0.317 & 1.434 & 1.069 \\
\hline $\mathrm{JP}$ & 0.213 & 0.033 & 0.269 & 0.172 & 0.285 & 0.046 & 0.359 & 0.198 & 1.339 & 1.406 \\
\hline NW & 0.652 & 0.174 & 0.979 & 0.022 & 0.723 & 0.138 & 0.929 & 0.271 & 1.109 & 0.789 \\
\hline $\mathrm{NZ}$ & 0.342 & 0.044 & 0.429 & 0.268 & 0.394 & 0.117 & 0.516 & 0.148 & 1.154 & 2.687 \\
\hline ES & 0.487 & 0.261 & 0.937 & -0.244 & 0.755 & 0.208 & 0.942 & -0.129 & 1.550 & 0.798 \\
\hline SD & 0.466 & 0.067 & 0.564 & 0.364 & 0.675 & 0.106 & 0.769 & 0.360 & 1.449 & 1.584 \\
\hline $\mathrm{OE}$ & 0.455 & 0.134 & 0.707 & 0.261 & 0.768 & 0.091 & 0.883 & 0.480 & 1.688 & 0.678 \\
\hline BG & 0.323 & 0.266 & 0.724 & -0.776 & 0.820 & 0.137 & 0.962 & 0.275 & 2.539 & 0.515 \\
\hline \multicolumn{11}{|c|}{ b) New EU markets } \\
\hline $\mathrm{CZ}$ & 0.341 & 0.082 & 0.527 & 0.194 & 0.559 & 0.175 & 0.721 & 0.188 & 1.642 & 2.142 \\
\hline $\mathrm{HN}$ & 0.337 & 0.185 & 0.767 & -0.219 & 0.518 & 0.238 & 0.905 & 0.022 & 1.536 & 1.290 \\
\hline $\mathrm{LN}$ & 0.425 & 0.105 & 0.740 & 0.067 & 0.502 & 0.192 & 0.850 & 0.146 & 1.182 & 1.827 \\
\hline $\mathrm{PO}$ & 0.414 & 0.123 & 0.702 & 0.160 & 0.566 & 0.178 & 0.860 & 0.223 & 1.366 & 1.445 \\
\hline $\mathrm{RM}$ & 0.394 & 0.187 & 0.825 & -0.086 & 0.498 & 0.256 & 0.914 & -0.117 & 1.266 & 1.371 \\
\hline SJ & 0.361 & 0.233 & 0.820 & -0.226 & 0.591 & 0.227 & 0.865 & -0.086 & 1.638 & 0.971 \\
\hline BL & 0.411 & 0.144 & 0.740 & 0.062 & 0.513 & 0.195 & 0.849 & 0.082 & 1.250 & 1.351 \\
\hline $\mathrm{CT}$ & 0.375 & 0.256 & 0.786 & -0.462 & 0.527 & 0.324 & 0.935 & -0.473 & 1.405 & 1.267 \\
\hline ET & 0.400 & 0.061 & 0.556 & 0.237 & 0.476 & 0.192 & 0.853 & 0.143 & 1.191 & 3.125 \\
\hline \multicolumn{11}{|c|}{ c) Asian markets } \\
\hline $\mathrm{CH}$ & 0.306 & 0.127 & 0.565 & -0.169 & 0.424 & 0.229 & 0.850 & -0.166 & 1.388 & 1.797 \\
\hline HK & 0.162 & 0.019 & 0.217 & 0.103 & 0.196 & 0.118 & 0.432 & -0.131 & 1.214 & 6.295 \\
\hline ID & 0.222 & 0.000 & 0.222 & 0.222 & 0.222 & 0.000 & 0.222 & 0.222 & 1.000 & 0.779 \\
\hline $\mathrm{KO}$ & 0.240 & 0.099 & 0.499 & -0.013 & 0.431 & 0.232 & 0.831 & 0.012 & 1.796 & 2.339 \\
\hline MY & 0.249 & 0.131 & 0.624 & -0.210 & 0.420 & 0.205 & 0.821 & 0.021 & 1.685 & 1.563 \\
\hline PK & 0.200 & 0.026 & 0.293 & 0.071 & 0.222 & 0.159 & 0.750 & -0.207 & 1.114 & 5.999 \\
\hline $\mathrm{TH}$ & 0.270 & 0.165 & 0.690 & -0.324 & 0.417 & 0.228 & 0.838 & -0.124 & 1.542 & 1.379 \\
\hline \multicolumn{11}{|c|}{ d) Middle East and African markets } \\
\hline EG & 0.225 & 0.016 & 0.355 & 0.180 & 0.226 & 0.053 & 0.380 & 0.064 & 1.004 & 3.332 \\
\hline IS & 0.422 & 0.114 & 0.794 & -0.041 & 0.520 & 0.201 & 0.896 & -0.304 & 1.233 & 1.764 \\
\hline SA & 0.381 & 0.169 & 0.737 & -0.007 & 0.520 & 0.243 & 0.894 & -0.072 & 1.364 & 1.442 \\
\hline TK & 0.317 & 0.264 & 0.840 & -0.169 & 0.415 & 0.244 & 0.803 & -0.123 & 1.307 & 0.925 \\
\hline \multicolumn{11}{|c|}{ e) Latin American markets } \\
\hline $\mathrm{BR}$ & 0.291 & 0.125 & 0.712 & 0.033 & 0.305 & 0.166 & 0.654 & -0.120 & 1.047 & 1.327 \\
\hline $\mathrm{CL}$ & 0.290 & 0.077 & 0.536 & 0.111 & 0.351 & 0.148 & 0.684 & -0.024 & 1.209 & 1.925 \\
\hline $\mathrm{CB}$ & 0.336 & 0.191 & 0.830 & -0.095 & 0.366 & 0.251 & 0.804 & -0.292 & 1.089 & 1.315 \\
\hline PE & 0.308 & 0.149 & 0.761 & 0.054 & 0.346 & 0.227 & 0.796 & -0.172 & 1.121 & 1.519 \\
\hline
\end{tabular}

Notes: Sample period: 1/1/2007 to 21/12/2009 with the Lehman collapse at 15/9/2008. Obs. 90 for the pre-

Lehman period and 66 for post-Lehman period. Mean Ratio and S.D. ratio is the ratio between pre-

Lehman and post Lehman CDS. 
Table 4 Panel analysis: Dependent variable $d c c_{t}$

\begin{tabular}{|c|c|c|c|c|c|c|}
\hline & \multicolumn{2}{|c|}{ All markets } & \multicolumn{2}{|c|}{ Developed markets } & \multicolumn{2}{|c|}{ Emerging markets } \\
\hline & Coef. & t-ratio & Coef. & t-ratio & Coef. & t-ratio \\
\hline Constant & $0.077 * * *$ & 20.901 & $0.109 * * *$ & 14.145 & $0.057 * * *$ & 15.035 \\
\hline$d c c_{t-1}$ & $0.816^{* * *}$ & 103.176 & $0.800 * * *$ & 60.535 & $0.831 * * *$ & 85.877 \\
\hline$e_{t-1}$ & 0.004 & 1.409 & $0.012 *$ & 1.700 & 0.002 & 0.573 \\
\hline$\Delta r_{t-1}$ & 0.000 & 0.110 & 0.004 & 0.045 & 0.000 & 0.107 \\
\hline$e_{t-1}^{u s}$ & 0.009 & 1.328 & 0.020 & 1.461 & 0.001 & 0.091 \\
\hline$\Delta r_{t-1}^{u s}$ & $0.174 * * *$ & 4.841 & $0.179 * * *$ & 2.507 & $0.172 * * *$ & 4.288 \\
\hline$d u m * e_{t-1}$ & $-0.013 * * *$ & -3.813 & $-0.021 * * *$ & -2.436 & $-0.013 * * *$ & -3.585 \\
\hline$d u m * \Delta r_{t-1}$ & 0.000 & -0.026 & 0.005 & 0.052 & 0.000 & 0.114 \\
\hline$d u m * e_{t-1}^{u s}$ & $-0.013^{*}$ & -1.719 & -0.016 & -1.103 & -0.008 & -1.033 \\
\hline$d u m * \Delta r_{t-1}^{u s}$ & $-0.330 * * *$ & -7.649 & $-0.355^{* * *}$ & -4.218 & $-0.313^{* * *}$ & -6.493 \\
\hline$R^{2}$ & & 0.785 & & 0.742 & & 0.753 \\
\hline$D W$ & & 2.202 & & 2.185 & & 2.216 \\
\hline F-test for fixed effect & & 5.806 & & 5.056 & & 2.898 \\
\hline [P-value] & & {$[0.000]$} & & {$[0.000]$} & & {$[0.000]$} \\
\hline F-test for dummies & & 34.571 & & 13.220 & & 23.369 \\
\hline [P-value] & & [0.000] & & {$[0.000]$} & & {$[0.000]$} \\
\hline
\end{tabular}

Note: $*, * *$ and $* * *$ significant at the 10,5 and $1 \%$ level. Fixed test is for cross-section. The estimates with the random effects are remarkably close to these of fixed effects, though for brevity, not reported here. The standardised coefficients are computed below by dividing the coefficients by the mean values of the respective variables.

Standardised coefficients (Table 4)

\begin{tabular}{cccc}
\hline & All markets & Developed markets & Emerging markets \\
\hline$e_{t-1}$ & 0.011 & 0.023 & 0.007 \\
$\Delta r_{t-1}$ & 0.002 & 0.060 & 0.0008 \\
$e_{t-1}^{u s}$ & 0.013 & 0.028 & 0.001 \\
$\Delta r_{t-1}^{u s}$ & 1.859 & 1.912 & 1.840 \\
$d u m * e_{t-1}$ & -0.220 & -0.061 & -0.040 \\
$d u m * \Delta r_{t-1}$ & 0.002 & 0.047 & 0.043 \\
$d u m * e_{t-1}^{u s}$ & -0.011 & -0.014 & -0.007 \\
$d u m * \Delta r_{t-1}^{u s}$ & -3.791 & -4.081 & -3.596 \\
\hline
\end{tabular}


Figure 1 Dynamic correlation (with the solid vertical line indicating the Lehman shock in September 2008)

a) Developed markets

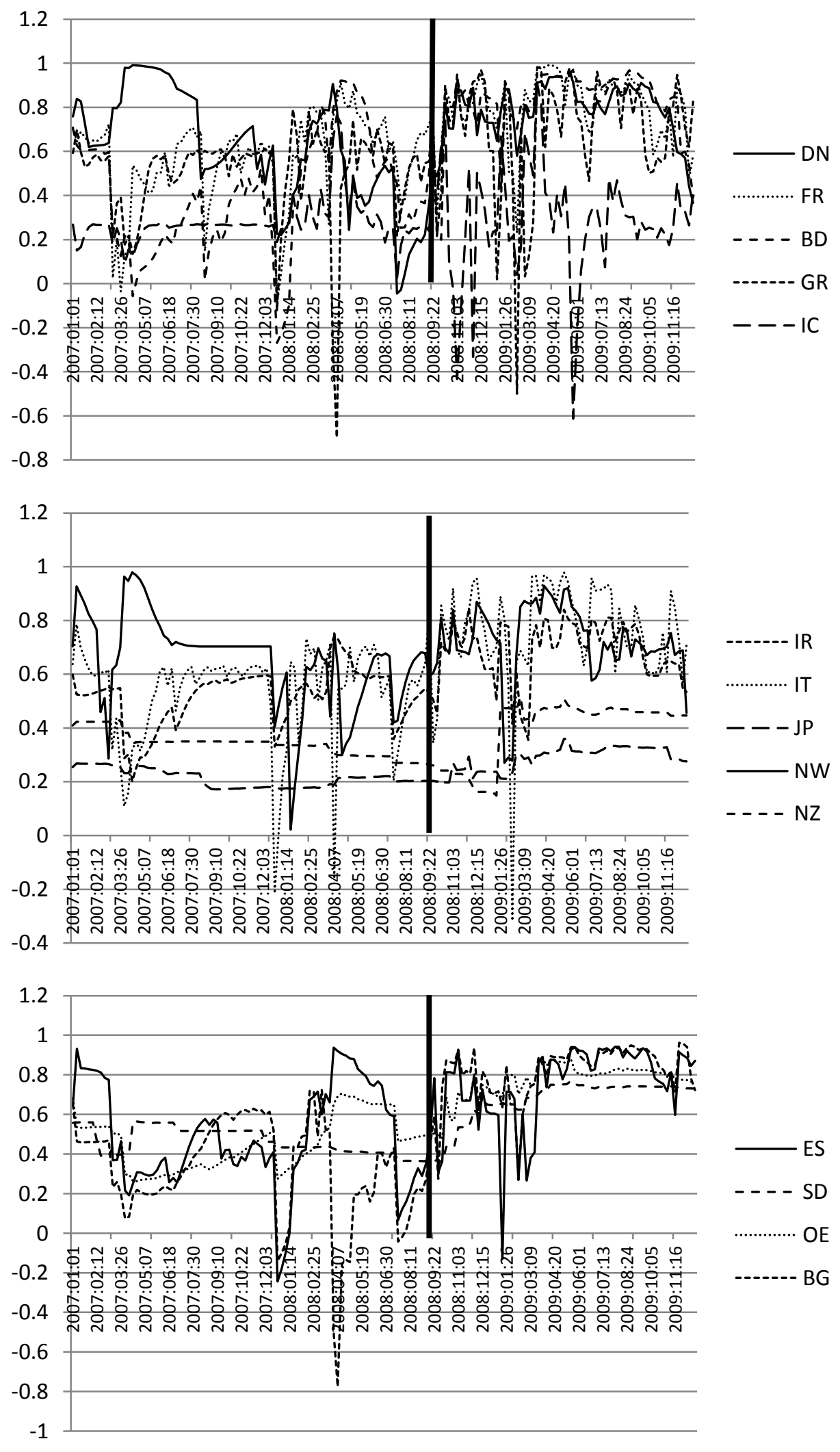


b) New EU markets
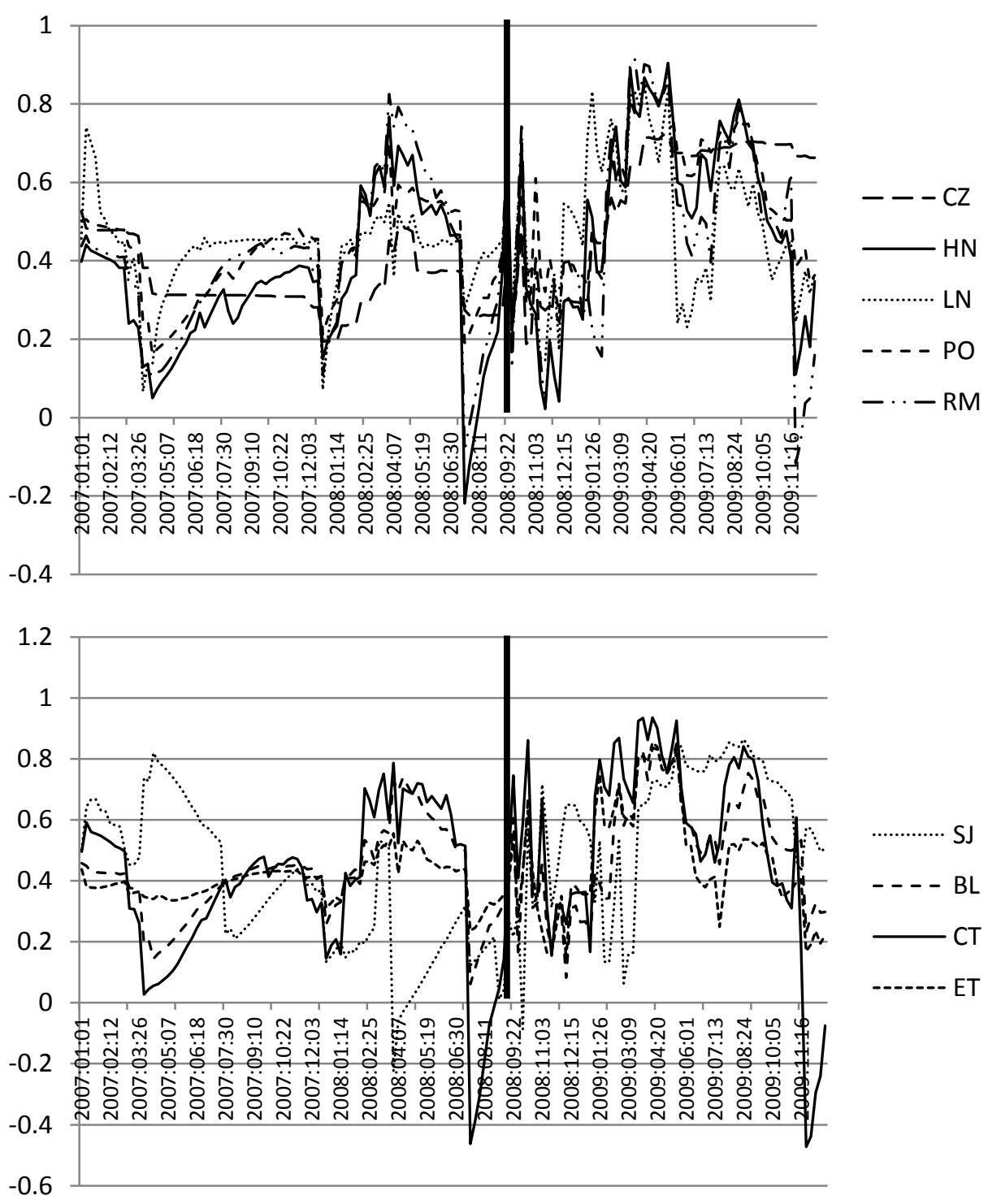
c) Asian markets
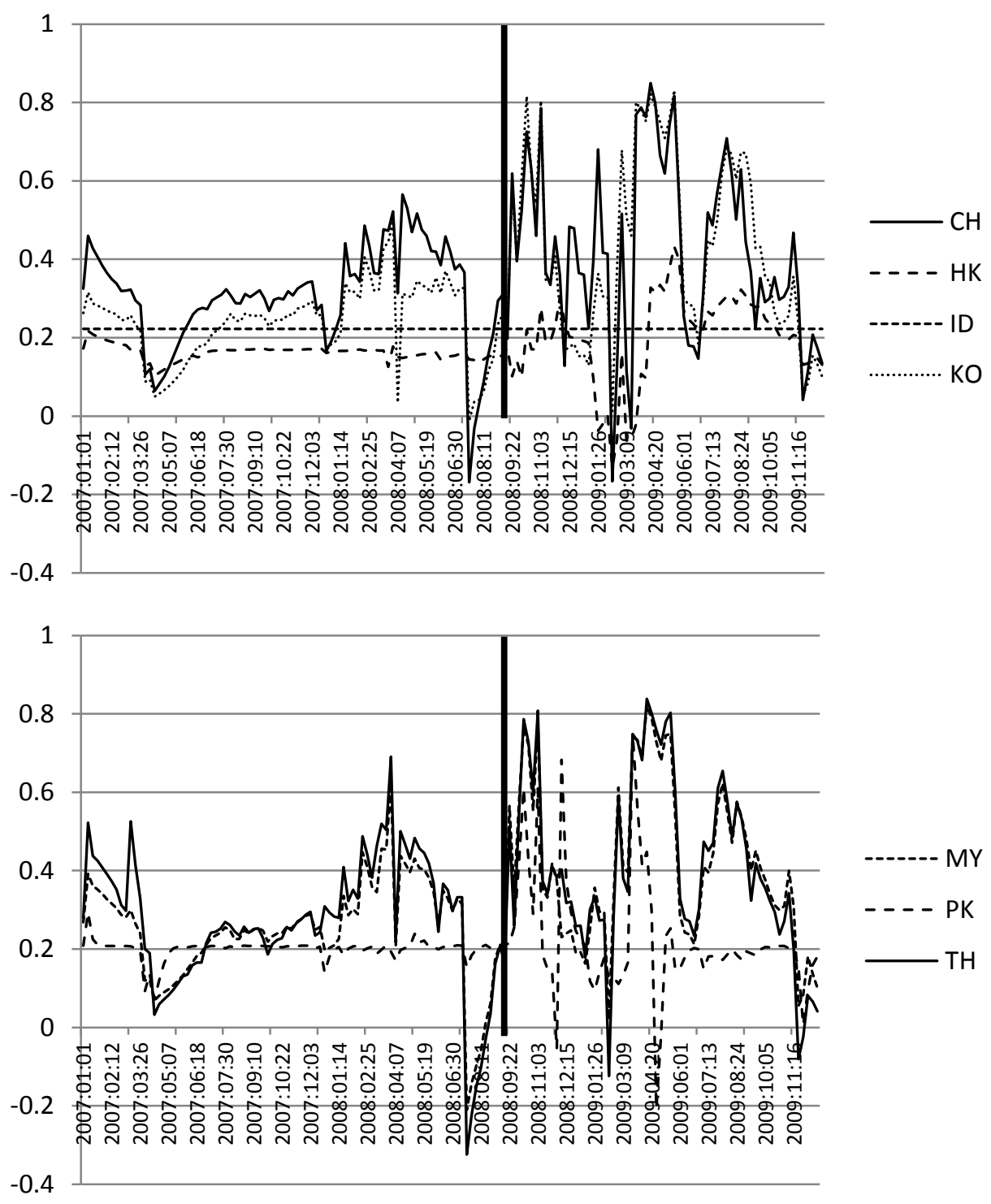
d) Middle East and African markets

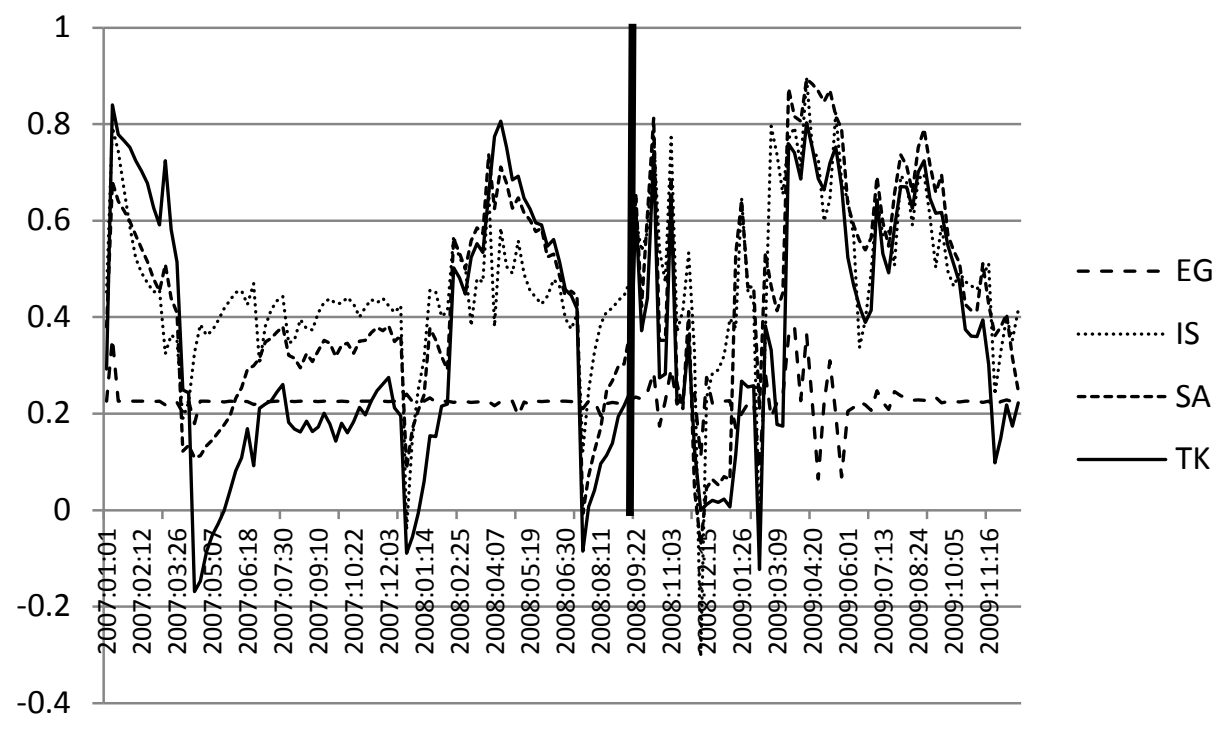

e) Latin American markets

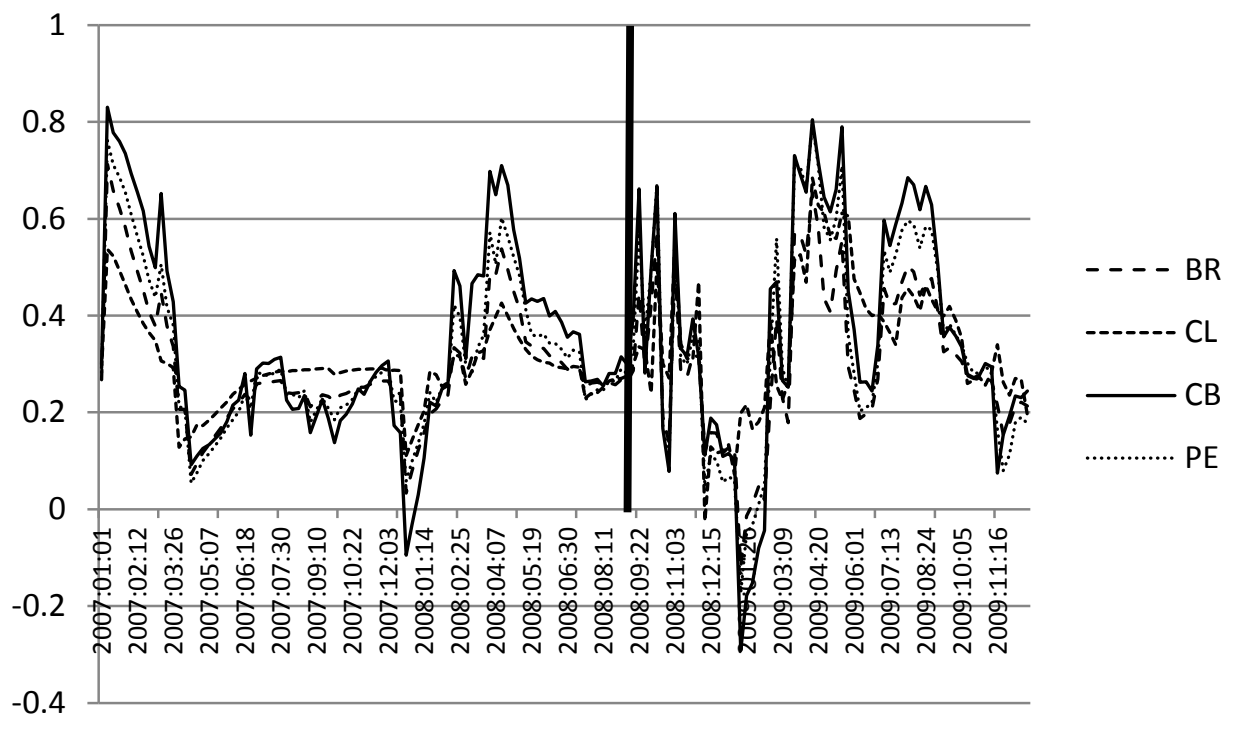

